\title{
BEYOND THE Q IMPASSE OR DOWN A BLIND ALLEY?
}

\author{
Mark Goodacre' \\ Department of Theology, \\ University of Birmingham, Edgbaston, \\ Birmingham. United Kingdom
}

\section{Introduction}

Beyond the $Q$ Impasse: Luke's Use of Matthew ${ }^{2}$ has been a long time coming. The catalyst for this volume was partly the Jerusalem Symposium on the Interrelation of the Gospels in 1984, when advocates of the Griesbach Hypothesis were encouraged to give a pericope-by-pericope demonstration of how Luke used Matthew alone-no Mark; no Q. But it is not just since 1984 that the world has waited for a book like this. In his Preface to this volume, William Farmer, the grandfather of the renewed quest for what has become known as "the Two-Gospel Hypothesis , ${ }^{3}$ points out that J.J. Griesbach only published a 'Demonstration

1. This paper was read at the Synoptic Problem Seminar of the SNTS at Birmingham, August 1997. I am grateful to the members of that seminar, and especially its chairs David Dungan and Albert Füchs, both for the invitation to speak and for some useful responses.

2. Allan J. McNicol, with David L. Dungan and David P. Peabody (eds.), Beyond the $Q$ Impasse: Luke's Use of Matthew. A Demonstration by the Research Team of the International Institute for Gospel Studies (Valley Forge, PA: Trinity Press International, 1996).

3. The authors' preferred name for their hypothesis is 'the Two-Gospel Hypothesis', used as a contrast to 'the Two-Source Hypothesis'. Michael Goulder, however, has argued that the term is 'confusing, and should be discontinued' on the grounds that 'my own theory, which is well-known to the Griesbachians, is also a Two-Gospel hypothesis, with Mark and Matthew the sources for Luke. So there are at least two Two-Gospel hypotheses. Griesbach has been known as the originator of the theory for two centuries, and his honourable name should be maintained.' 
that Mark was Written After Matthew and Luke'. ${ }^{4}$ Undertaking the twin demonstration, 'Luke's use of Matthew', is the task of this latest piece of research, after a gap of over two hundred years. ${ }^{5}$

Beyond the $Q$ lmpasse is, then, something of a milestone in synoptic criticism. Here, for the first time, we have a painstakingly researched, detailed presentation, replete with lists, summaries, charts and synopses, of exactly what was involved in the writing of Luke's Gospel on the hypothesis that Matthew was his primary substantial written source.

The authors are the six Fellows who make up the Research Team of the International Institute for Gospel Studies, ${ }^{6}$ and it is a remarkable piece of collaborative research. ${ }^{7}$ In spite of the detail, the procedure is straightforward. The introduction charts the place of this book in the history of synoptic criticism, outlines the sequential and linguistic evidence for Luke's use of Matthew, pauses to consider Luke's use of nonMatthaean tradition, and comments on Luke's compositional techniques and major themes as they emerge from the thesis of Luke's use of Matthew.

This introduction is followed by nearly 300 pages of what is called 'compositional analysis of the Gospel of Luke according to the Two Gospel Hypothesis'. This analysis follows the same pattern through-

('Luke's Knowledge of Matthew', in Georg Strecker [ed.], Minor Agreements: Symposium Göttingen 1991 [Göttingen: Vandenhoeck \& Ruprecht, 1993], pp. 14360 [p. 143 n. 1]).

4. Johann Jakob Griesbach, Commentatio qua Marci Evangelium totum $e$ Matthaei et Lucae commentariis decerptum esse monstratur (Jena, 1789-90), translated by Bernard Orchard as 'A Demonstration that Mark Was Written after Matthew and Luke', in Bernard Orchard and Thomas R.W. Longstaff (eds.), J.J. Griesbach: Synoptic and Text-Critical Studies 1776-1976 (Cambridge: Cambridge University Press, 1978), pp. 103-35.

5. There have, however, been forerunners: J. Bernard Orchard, Matthew, Luke and Mark (Manchester: Koinonia, 1976) and Harold Riley, Preface to Luke (Macon, GA: Mercer University Press, 1993).

6. The Institute is sometimes called the International Institute for the Renewal of Gospel Studies. Members of the Research Team are Lamar Cope, David Dungan, William Farmer, Allan McNicol, David Peabody and Philip Shuler. Thomas Longstaff is also a member of the team though he was not directly involved with this book.

7. It is particularly remarkable that the book keeps a uniform style throughout, with no signs of the six different hands at work. I at least found it impossible to do any source- or redaction-criticism on the text with a view to discovering who wrote what. 
out. ${ }^{8}$ The Gospel is divided into seven parts (Lk. 1-2; 3.1-4.16a; 4.16b$7.15 ; 7.16-9.50 ; 9.51-19.27 ; 19.28-21.38$ and $22-24)$, each of which is introduced before there is discussion of 'sections' and then pericopae. Each pericope is discussed first under 'general observations', usually of a source-critical nature, and then 'verse-by-verse observations'.

The whole is nicely peppered with excursuses and synopses. The latter are especially important to the Research Team who frequently express scepticism about all current printed synopses, which, they feel, unduly bias the reader in favour of the Two-Source Hypothesis. ${ }^{9}$ And the synopses of particular passages in this book are indeed useful, often showing up parallels that are not normally noticed. The sequential parallel between Lk. 11.27-28 and Mt. 12.46-50 (par. Mk 3.31-35; Lk. 8.19-21) first noticed by Michael Goulder, for example, ${ }^{(1)}$ is helpfully set out (p. 179) with the comment 'No synopsis currently in print shows these connections' (p. 180).

Indeed, the presentation of the book is generally most helpful. Before commenting on each pericope, the authors give a convenient (and sometimes lively) summary of its content, usefully orientating the reader who has the book on a train journey, and no Bible to hand. The opposite pitfall, of superficiality, is avoided too. The careful lists, summaries and synopses often facilitate good, detailed study by the reader who wants to check carefully the claims that are made in the text.

The biggest treat, though, is one that might easily be missed. Tucked inside a pocket at the back of the book are four fold-out charts, each cleverly depicting what is involved, on the Griesbach Hypothesis, in Luke's re-ordering of Matthew. Chart A deals with Luke 3-10, Chart C with the Travel Narrative and Chart D with the Passion Narrative. Chart B provides a slightly different way of looking at the thesis as it relates to Luke 3-10. These charts are all crystal clear and a helpful way of

8. The only major alteration in presentation comes in Part Five (Lk. 9.5119.27) when a fresh section, 'Source-critical observations', is introduced because of the greater complexity of discussing the Travel Narrative (see p. 151).

9. See, for example, p. xiii where Farmer predicts 'a sweeping reevaluation of basic assumptions undergirding contemporary Gospel research...not excluding the critical instruments so many take for granted: the gospel synopsis and the critical text'.

10. Michael Goulder, 'The Order of a Crank', in C.M. Tuckett (ed.), Synoptic Studies: The Ampleforth Conferences of 1982 and 1983 (JSNTSup, 7; Sheffield: JSOT Press, 1984), pp. 111-30 (p. 118); and Michael Goulder, Luke: A New Paradigm (JSNTSup, 20; Sheffield: JSOT Press, 1989), pp. 509-11. 
orientating oneself while working through the text. I found it useful on several occasions to have one or other of the charts open while I studied the book. These charts are valuable contributions to synoptic criticism-it would be more than useful if this were to be imitated in the future by proponents of alternative positions. ${ }^{1}$

\section{Strategy}

But if there is much to commend in this book's scope. as well as in its care and clarity, what is one to say about its argument? The first thing that strikes the reader is the authors' boldness:

The net result of this study is, then, that we believe that more than a demonstration that Luke might have used Matthew as his source has been achieved. We believe that it will be difficult to argue that the data in Luke can be explained any other way than that Luke was thoroughly conversant with canonical Matthew and made it the basis of his Gospel (pp. 318-19; italics original).

The book thus 'presages the beginning of an exciting new era in New Testament studies' (p. 319).

These conclusions do not come out of the blue. Rather, they are frequently foreshadowed, determining the authors strategy during the course of the book. 'Demonstration', for example, is a key term. Inherited from the title of Griesbach`s original thesis, and used as part of the subtitle of this book, its use is revealing. Beyond the $Q$ Impasse sometimes simply delivers the data-the evidence, it is thought, is so overwhelming, that it speaks for itself. At most, after the presentation of the data, a small rhetorical question is asked, as on p. 177: 'How would advocates of the "Q" hypothesis refute this web of evidence?", or a sober summary statement is given. as on p. 170: 'This constitutes further evidence of the secondary nature of Luke to Mt.'

This kind of strategy has values. The rhetorical force of attempting to demonstrate rather than to argue one's case lends to the whole the persuasive force of advocacy. Little is conceded to opponents whose views, at best, recede quietly into the background. Further, by avoiding dialogue with opposing positions, more space can be allotted to bring

11. One is reminded of the recently re-issued classic chart of Allan Barr, A Diagram of Symoptic Relationships (Second Edition with a New Introduction by James Barr, Edinburgh: T. \& T. Clark, 1995 [1938]). 
forward the all-important primary textual evidence.

But the strategy is also a vulnerable one. By avoiding opportunities to argue with opponents, the authors deprive themselves of a potentially helpful tool. For if the hypothesis is to succeed, one surely requires not just the rhetoric but also some debate. If indeed the case for Luke's use of Matthew alone is so overwhelming, why not demonstrate its superiority over the Two-Source Theory at given points? Such dialogue is rare in the book, and is not even found in footnotes.

Further, it is striking that, on the whole, the authors do not grant themselves the luxury of quoting their friends-they rarely acknowledge and hardly ever interact with those who might have made their task easier. I was surprised, for example, to find no reference to Austin Farrer, whose seminal article 'On Dispensing with $Q^{12}$ was surely the starting point for the re-opening of the Q question. ${ }^{13}$ On the other hand, Beyond the $Q$ Impasse does refer frequently to Goulder's recent Luke: A New Paradigm, though even here it is usually in connection with Goulder's linguistic data, often missing points at which his arguments could have helped the authors to buttress and finesse their case.

The discussion of the Minor Agreement between Mt. 4.13 and Lk. 4.16 over N $\alpha \zeta \alpha \rho \alpha$ (pp. 82-82) provides a good illustration of the strengths and weaknesses of the book's strategy. There is a synopsis of the relevant passages (p. 82), with key words underlined, and there follows a list of the 'various spellings of 'Nazareth' in the Gospels' (p. 83). Both the synopsis and the list are clear and illuminating. But there is no reference to any of the relevant secondary literature, whether by friend or foe ${ }^{1+}$ and the value of the material is accordingly compromised.

12. Austin Farrer, 'On Dispensing with Q', in D.E. Nineham (ed.), Studies in the Gospels: Essays in Memory of R.H. Lightfoot (Oxford: Basil Blackwell, 1955), pp. 55-88.

13. In the section on 'Our historical context', the authors go straight from Butler to Farmer (p. 9). It should be added that due weight has been given to Farrer in other Griesbachian works, for example William R. Farmer, 'Certain Results Reached by Sir John C. Hawkins and C.F. Burney which Make More Sense if Luke Knew Matthew and Mark Knew Matthew and Luke', in Tuckett (ed.). Synoptic Studies, pp. 75-98.

14. There is extensive discussion of the issue in favour of Luke's use of Matthew in Michael Goulder, 'On Putting Q to the Test', NTS 24 (1978), pp. 218-34 (219-21); Luke: A New' Paradigm, pp. 306-307; 'Luke's Knowledge of Matthew', pp. 144-48. For comment on this and references to further literature, see my 
Moreover, it might prove dangerous to avoid any substantial interaction with the scholarship for another reason. Whether one likes the fact or not. those who want to go 'beyond the Q impasse' are in the minority. There may well be an increasing number of scholars dubious about one or other aspect of the standard solution to the synoptic problem. but this observation needs to be placed in context. The majority of contemporary New Testament scholars are simply uninterested in the hard work of mastering the study of the Synoptic Problem. They think that, but for a vocal minority of nuisances, $Q$ is consensus. It is the status quo-and there are many more interesting problems to be explored without wasting time "digging up old foundations".

It is important in such circumstances to ensure that one is engaging not only with those who have expertise in the Synoptic Problem but also with others whose skills are in different fields. This is particularly the case in relation to scholarship on Luke's Gospel. It is unusual, after all, to read a 300-page book on Luke's Gospel without any reference to Conzelmann. Nor is there reference to Bultmann, Schürmann. Jeremias, or Jack Sanders, C.H. Talbert or Christopher Evans, to name just a few. There is a brief reference to Cadbury (p. 29), but no interaction with his seminal work. ${ }^{15}$

The attempt to 'renew Gospel Studies', the fundamental aim of the International Institute whose Research Team has written this book, could be all about both showing where traditional Two-Source-based scholarship has gone wrong, and interacting with the conclusions of the great works where they are on the right lines. If the Research Team want the world at large to be affected by their attempts at revolution, the future will surely have to involve greater interaction with key scholarship, both inside and outside of the narrow confines of specifically Synoptic debate. ${ }^{16}$

Goulder and the Gospels: An Examination of a New Paradigm (JSNTSup, 133; Sheffield: Sheffield Academic Press, 1996), pp. 101-102.

15. For a critique of H.J. Cadbury, The Style and Literary Method of Luke (Cambridge, MA: Harvard University Press, 1920) from a Griesbachian perspective, see J.G.F. Collison, 'Linguistic Usages in the Gospel of Luke', in W.R. Farmer (ed.). New Synoptic Studies: The Cambridge Gospel Conference and Beyond (Macon, GA: Mercer University Press, 1983), pp. 245-60. There is no reference in the current volume, however, to H.J. Cadbury's treasure trove, The Making of Luke-Acts (London: SPCK, 1958).

16. There is a sense too in which most works of scholarship are works of propaganda, and the Research Team would do themselves no harm by using the names of 
Lest this criticism seem somewhat harsh, I will point to two places at which greater engagement with secondary literature might have helped their case, the first one narrowly synoptic, the second broadly Lukan. First, then, after discussing Lk, 4.31-32, 4.14-16 and 7.1 (p. 23) as evidence for Luke's use of Matthaean summary passages (Mt. 7.28-29, etc.) and thus 'evidence of Luke's direct use of Matthew', we find the statement: 'None of this kind of phraseology is considered by anyone to come originally from a pre-Matthean source like the hypothetical Q' (p. 23).

This is simply incorrect. The International Q Project's reconstruction of the 'critical text of Q' includes both Q 7.1 and Q 4.16. ${ }^{17}$ One might, of course, want to disagree with their decision to include these verses, or think that their presence in a reconstructed Q causes problems for the Two-Source Theory, but if so it might be wiser to document a response than to by-pass the debate.

On the second, broader issue, there is a fine discussion in the introduction to Beyond the $Q$ Impasse on 'Luke's Compositional Techniques' (pp. 29-33). This is some of the strongest material in the book, engaging with Lucian of Samosata's How to Write History and showing how this can make good sense of Luke's compositional procedure on the assumption of his use of Matthew alone. For all the merit of this piece, however, with its key implications for the 'compositional analysis' that makes up the rest of the book, the authors weaken its value by treating it in isolation from any of the substantial secondary literature

its (partial) friends to lend credence to their claims. I notice, for example, no reference (except in the bibliography) to the work of E.P. Sanders (formerly supervised by William Farmer) whose well-known scepticism for Q might have helped their cause. See particularly E.P. Sanders and M. Davies, Studying the Synoptic Gospels (London: SCM Press; Philadelphia: Trinity Press International, 1989), Part Two of which features some balanced and scholarly consideration of the Griesbach hypothesis.

17. For the International Q Project Reconstructions, see $J B L 109$ (1990), pp. 499-501; 110 (1991), pp. 494-98, 111 (1992), pp. 500-508; 112 (1993), pp. 500506; 113 (1994), pp. 495-500; 114 (1995), pp. 501-11; 116 (1997), pp. 521-25. The International Q Project is now engaged in the production of 31 volumes in a series entitled Documenta $Q$. The first five of these are already published, one of the most recent covering precisely this verse: Shawn Carruth and James Robinson, Documenta $Q: Q$ 4.1-13, 16: The Temptations of Jesus; Nazara (ed. Christoph Heil; Leuven: Peeters, 1997). So, too, H. Schürmann, Das Lukasevangelium (HTKNT, 3.1; Freiburg: Herder, 1969), p. 391, places Lk. 7.1 in Q. 
on Luke's literary achievement. This inadvertently gives the impression that Luke's writing ability is a matter properly appreciated only by adherents of the Griesbach hypothesis. Reference to recent writers like Luke Johnson, ${ }^{18}$ or to older ones like Henry Cadbury, ${ }^{19}$ who celebrate Luke's literary skill (and who themselves refer to Lucian) would surely aid the presentation. It is true that such scholars believe in Q, but undue suspicion of scholars tainted with the Two-Source Hypothesis could be a major stumbling-block. After all, the Griesbachian agenda might best be served by corroborating the conclusions made by those like Johnson, and then attempting to show that these very conclusions make more sense on Griesbachian assumptions. ${ }^{20}$

\section{Methodology}

From Farmer's famous Synoptic Problem ${ }^{21}$ to the present, one of the key contributions to scholarship made by adherents of the Griesbach Hypothesis has been a stress on the importance of proper methodology in synoptic study. The present volume is no exception in its concern to use good, critical methods. One section of the introduction (pp. 8-10) is specifically devoted to 'Breaking free of the circular process', and it features a nice quotation from B.C. Butler which criticizes Streeter, Abbott. Burkitt. Wellhausen and probably Hawkins for falling victim to

18. See, for a good starting point, Luke Johnson, 'Luke-Acts, Book Of', $A B D$ IV, pp. 404-20, especially pp. 405-406. Johnson's statements that 'His [Luke's] narrative is essentially linear, moving the reader from one event to another' and 'Instead of inserting great blocks of discourse into the narrative, Luke more subtly interweaves deeds and sayings' (p. 406) are quite consonant with the Griesbachian claims in Beyond the $Q$ Impasse.

19. See n. 15. Cadbury refers to Lucian (and other classical writers) particularly in Making, Chapter 15, 'Literary Formalia'.

20. It is also the case that the authors make many conclusions conducive to mainstream scholarship, but potentially alienate themselves from making a contribution to that scholarship by not interacting directly with it. The summary on $p$. 185, for example, is as good a summary of Luke's Central Section as one can find: 'The Travel Narrative served Luke as a literary device for presenting long collections of Jesus' teachings within a narrative context'. Such gems can get lost, however, embedded in the heart of a compositional analysis that does not acknowledge the works of Two-Source Theorists.

21. William R. Farmer, The Synoptic Problem: A Critical Analysis (New York: Macmillan, 1964; repr. Dillsboro, NC: Western North Carolina Press, 1976). 
'a schoolboyish error of elementary reasoning at the very base of the Two Document Hypothesis' (p. 9).22

So, is the current volume free from hints of circular reasoning? The answer, unfortunately, is that it is not. In one important respect, there is circularity in the basic conceptualization of the project. The authors believe that Luke used Matthew alone and the book is an attempt to analyse Luke, pericope by pericope. on this basis. The usual appeals to Markan priority thus drop out of the equation. The method appears sound but there is a problem, a problem that can most clearly be explained by illustration. In their discussion of Lk. 4.31-37, the authors write:

The account of the exorcism given here is unique to Luke, possibly coming from his nonMatthean tradition (p. 88).

They go on to elaborate that Lk. 4.31-32 finds a parallel in Mt. 7.2829 , and they comment:

This material was created by Matthew to situate the Sermon on the Mount in his narrative. What we have here is clear evidence that Luke has carefully avoided all of the Sermon on the Mount (saving it for later use) and, following the Matthean transitional material around the Sermon on the Mount, has, through the paraphrase of Mt 7.28-29, created a new scene in Capernaum (cf. Mt 8.5), whose basic purpose was to provide ironic contrast to the disastrous ending to Jesus' visit to Nazareth. This appearance of redactional material from the Gospel of Matthew in Luke is strong evidence that the hypothetical Q source is unnecessary (p. 89).

The basic difficulty with this argument is that it ignores the hypothesis of Markan priority. To some extent this is natural, of course, in a book that presupposes Markan posteriority. But when the presupposition becomes bound into the argument, only circularity can result. To say, for example, that Lk. 4.31-37 is 'unique to Luke' is at best misleading since the pericope is one which, on the standard theory, derives from $M k$ 1.21-28, a fact that is not even mentioned..$^{23}$

Further, the argument works by isolating 'redactional' material in Matthew (Mt. 7.28-29), and demonstrating Lukan dependence on it

22. Quoting B.C. Butler, The Originality of St Matthen: A Critique of the Two Document Hypothesis (Cambridge: Cambridge University Press, 1951), p. 63.

23. See, similarly, p. 257 on Lk. 21.1-4, 'this unique account', with no reference to the parallel in $\mathrm{Mk}$ 12.41-44. 
(Lk. 4.31-32), thereby apparently eliminating Q. But this argument will not convince those who believe in Markan priority, for whom Mt. 7.2829 utilizes phraseology from Mk 1.21-28, the pericope on which Luke is dependent for 4.31-37. Thus, Matthew borrows from Mark and so does Luke-this is not the least bit difficult for the standard theory, and 'the hypothetical Q source' has got nothing to do with it. In other words, the relevant phraseology in Mt. 7.28-29 is only 'created by Matthew' if one does not believe in Markan priority-and material that counts as 'strong evidence' for a position only when it works on the assumption of that position is unhelpful. By ignoring the standard explanation of the data, and hence any reference to Mark, the authors have here neutralized any value that their argument might otherwise have had, and have bound themselves into a circle.

It should perhaps be noted in the authors' defence that the aim of the book is to provide a 'demonstration' that Luke has read Matthew alone, and to 'take Mark completely out of the picture' (p. 12), and it is arguable that this will involve an inevitable degree of circularity. What needs to be investigated, therefore, are the specific goals that the book sets itself: in what ways, and using what methodology, does it claim to demonstrate 'Luke's use of Matthew'?

In the introduction the Research Team specify two types of evidence (pp. 13-24), the first 'sequential' and the second 'linguistic', both of which are repeated themes of the compositional analysis that comes afterwards. The choice of these two types of evidence is surely a good move. These are different but complementary ways which, if established. might militate against Q. Let us take each in turn.

\section{Order}

The question of order is clearly a crucial one for the thesis. After all, one of the traditional objections to Lukan knowledge of Matthew has been the issue of order: why would Luke have spoiled Matthew's fine arrangements, and especially the Sermon on the Mount? ${ }^{2+}$ In the current

24. One of the most strident of recent statements on this is quoted by the Research Team on p. 11: 'Why would Luke have wanted to break up Matthew's sermons, especially the Sermon on the Mount, incorporating only part of it into his Sermon on the Plain and scattering the rest of it in an unconnected form in the loose context of the travel account?' (Joseph Fitzmyer, The Gospel According to Luke IIX (AB, 28; Garden City, NY: Doubleday, 1981), p. 74. 
volume, the authors see Luke. broadly, as behaving in slightly different ways at different points in the narrative. Luke 1-2 (Part One) is a radical reworking of Mt. 1-2 (pp. 15 and 47-69). Luke 3.1-9.50 (Parts Two, Three and Four) has Luke making a 'cyclic progression' through Matthew 3-18.5, 'moving forward and going back again, selecting Matthean units and combining them with materials of his own to create his chronologically-oriented narrative' (p. 21; see also pp. 15-19; 71149; Charts A and B). In Luke 9.51-19.27 (Part Five), the evangelist 'combined materials taken from Mt's speeches and unused narratives with nonMatthean tradition to create a lengthy series of teaching scenes for the guidance and instruction of the Christian churches in the international mission area' (p. 17; cf. p. 147). Finally come Parts Six and Seven (Lk. 19.28-24.53) in which 'Luke followed the basic narrative order of Matthew 19-28, considerably revising the content of each narrative unit', adding non-Matthaean material at the end in preparation for Acts (p. 21; see also pp. 20 and 245-317; Chart D).

How far do the Research Team succeed in making good sense of Luke's order? First, it should be said that the admirable clarity with which the authors have set out the data adds to the coherence of the thesis. Chart A is particularly helpful (pp. 16-17, reproduced also separately in the back-cover pocket), illustrating in five Lukan columns, set in parallel to one Matthaean column, exactly how the "cyclic progression' is seen to work. And it has to be added that the procedure outlined is at least possible, and this marks an important advance in the explanation and defence of the Griesbach Hypothesis.

Nevertheless, there are qualms. ${ }^{25}$ First, three of the five cycles feature (acknowledged) exceptions to the supposed orderly progression through Matthew that each of them is supposed to represent-in the first column John the Baptist's Imprisonment (3.19-20) and the Genealogy (3.23-38) are 'transposed'; in column 2 it is Jesus' Call of the Twelve (6.12-16); and in column 3 it is True Relatives (8.19-21). Given that there are five separate 'columns', covering only a chapter and a half of Luke each, the material is already spread pretty thinly. and exceptions are important.

Second, hypotheses are often best tested by asking the question whether they make better sense of the same data than do their rivals. Here it needs to be noticed that most of the 'cyclic progressions' would straightforwardly be explained on the Two-Source Hypothesis by appeal

25. I am grateful to Stephen Carlson for some helpful discussion of this material. 
to the order of Mark and the (supposed) order of Q. Thus Columns 2 and 4 feature almost entirely Markan material, and the similarity in order is explained by dependence on Mark. Column 5 is entirely $Q$ material, and so in the Q order; column 3 is mainly $\mathrm{Q}$ material, and so again in the $\mathrm{Q}$ order. Column 1, on the other hand, is more difficult for the Two-Source Theory, which can only explain the move from Nazareth to Capernaum by placing N $\alpha \zeta \alpha \rho \alpha$ in $Q{ }^{26}$

Not surprisingly, Luke 9.51-19.27 turns out to be less straightforward. The data is more complex and less amenable to clear illustration in a chart. Impressively, though, clear illustration is achieved (Chart C). Further, since making sense of the Central Section on the assumption of Luke's knowledge of Matthew is a well-known difficulty, the Research Team should be commended for their prudent judgment in not adding to the volumes of contrived theories on Luke's order here. The approach they take is partly literary. partly thematic. Luke selects some Matthaean, some non-Matthaean material, keeping to Matthew's order at times, departing from it at other times, all in the service of his literary goal to provide 'a series of edifying themes' against 'the backdrop of Jesus' journey toward Jerusalem' (see Chart C).

Now it is unlikely that the argument will convince $Q$ theorists, for whom there is a ready explanation of Luke's order in Q. Since no-one has ever seen $\mathrm{Q}$ (outside of the reconstructions that take for granted that Luke's order is, largely, Q's order), and since this is one of the planks on which the Q hypothesis is traditionally based, it is always going to be difficult to make the case for Luke's use of Matthew.

The Research Team have, however, made an important step forward here, and it should not be missed. In making a positive evaluation of Luke's literary achievement in the Travel Narrative, and by linking this with the source issue, the authors have effectively begun to undermine one of the pillars of the Q hypothesis, the negative evaluation of Luke's order in the Central Section. As long as Luke's order in the Central Section is regarded as incomprehensible, recourse to a conservative dependence on a hypothetical lost source seems necessary. As soon as one begins to value Luke's creative expertise, his use of Matthew becomes more plausible. Or, to put it the other way round, the more that

26. As is done by several $Q$ theorists who have spotted the difficulty-Streeter, Schürmann, Tuckett and Catchpole among them (for details, see my Goulder and the Gospels, p. 102 n. 33). See now also Documenta $Q: Q 4.1-13,16$, The Temptations of Jesus; Nazara (n. 17 above). 
those who believe in Q appreciate Luke's literary ability, the more the argument that Luke's order equals Q's order will break down. The contribution to scholarship made by Beyond the $Q$ Impasse is in this regard a most useful one.

\section{The Linguistic Argument}

There are, then, some pleasant surprises, as well as niggling difficulties, in the argument from order. What, then, of the other repeated argument, that from language? Here the authors of Beyond the $Q$ Impasse coin a new phrase, 'one-way indicator', to refer to words, phrases and constructions that show signs of Matthew's hand and that occur in close sequential, narrative parallel in Luke. Such 'one-way indicators', introduced on pp. 21-24, and much stressed in the compositional analysis, are held to be 'strong evidence' for 'Luke's use of Matthew'.

Before looking at these in more detail, though, we should look at the tools used for the analysis. For just as the Research Team are suspicious of traditional synopses, so too they are (implicitly) critical of traditional tools used for the analysis of language like Hawkins's Horae Synopticae. ${ }^{27}$ It is important to them to be 'using impartial instruments' (p. 12). Three main tools are used. The most extensive is Franklyn J.G. Collison's unpublished doctoral dissertation, 'Linguistic Usages in the Gospel of Luke'. ${ }^{2 x}$ Similarly, for Matthew's linguistic usages, appeal is made to Dennis G. Tevis's 'An Analysis of Words and Phrases Characteristic of the Gospel of Matthew'. ${ }^{29}$ Third, Michael Goulder's Luke: A New Paradigm ${ }^{30}$ is used to supplement these.

It would be a mistake, however, to regard these tools as being entirely 'impartial'. Goulder's Luke, for example, like many of the comparable treatments of characteristic vocabulary, needs to be treated

27. J.C. Hawkins, Horae Synopticae: Contributions to the Study of the Synoptic Problem (Oxford: Clarendon Press, 2nd edn, 1909).

28. Franklyn J.G. Collison, 'Linguistic Usages in the Gospel of Luke' (PhD dissertation, Southern Methodist University, 1977). This is available from University Microfilms International. Ann Arbor, Michigan 48106. For details, see http.//www.umi.com/hp/Suppor/DExplorer/tind/.

29. Dennis G. Tevis, An Analysis of Words and Phrases Characteristic of the Gospel of Matthew' (PhD dissertation, Southern Methodist University, 1983), also available from UMI (see previous note).

30. See n. 10 . 
with care. Such lists almost always feature elements of circularity, ${ }^{31}$ and Collison, who works on the assumption of the Griesbach hypothesis, is not exempt from the same criticism. ${ }^{32}$

Further, the reader used to using works like Hawkins and Cadbury will be surprised to see so little reference to them, for their conclusions are often congenial to the Griesbach Hypothesis. ${ }^{3{ }^{3}}$ One of the Research Team's key 'one-way indicators' (Mt. 26.47 // Lk. 22.47), for example, is a grammatical instruction listed by Hawkins, i $\delta o v$ + genitive absolute. ${ }^{3+}$

However, the suspicion of Hawkins, Cadbury and company issues forth largely from the Research Team's desire, to which I have already made reference, to 'tak[e] Mark completely out of the picture' (p. 12), and to consider Luke and Matthew in their own right. Laudable methodologically as this task appears, in this context too it promotes circularity.

Some stress, for example, is placed on Luke's use of $\sigma \kappa \alpha v \delta \alpha \lambda i \zeta o \mu \alpha \mathrm{l}$ in 7.23 and 17.2 (pp. 24 and 115 ) ${ }^{35}$ both times in parallel with Matthew (11.6 and 18.6 respectively). The authors comment:

This word occurs sixteen times in various contexts in Matthew but only twice in Luke, both in passages that are closely parallel to the Matthean order of narration. Again this is evidence that Luke got this word from Matthew (p. 24).

The difficulty with this is that the word is only strongly characteristic of Matthew if one ignores the evidence from Mark, where it occurs eight times, on one occasion in parallel to Luke $17.2 !^{36}$ Of course

31. See my Goulder and the Gospels, pp. 44-47.

32. I do not have the space here to justify this claim concerning Collison's careful, detailed and valuable dissertation, but I hope to publish a more detailed investigation in due course.

33. See here Farmer's 'Certain Results' (n. 13 above) which makes this point concerning some of Hawkins's data.

34. Occurrences of the construction are listed by J.C. Hawkins, Horae Synopticae, p. 31. This is also one of my own examples of six Minor Agreements that satisfy Goulder's criteria of being both positively Matthaean and positively unLukan-see Goulder and the Gospels, p. 116, and the response by F. Neirynck, 'Goulder and the Minor Agreements', ETL 73 (1997), pp. 84-93 (pp. 89-91).

35. The Research Team do not comment on its occurrence in 17.2 in the compositional analysis (p. 229), though they do comment on $\sigma \kappa \alpha \dot{v} \delta \alpha \lambda \alpha$ in 17.1.

36. It should, however, be added that the evidence from $\sigma \kappa \alpha v \delta \alpha \lambda i \zeta o \mu \alpha 1$ is more impressive than the Research Team make it. $\sigma \kappa \alpha v \alpha \lambda i \zeta o \mu \alpha l \dot{\varepsilon} v$ is listed by Hawkins, 
Griesbachians would object that on their hypothesis Mark is here irrelevant, and will have taken over his usages of $\sigma \kappa \alpha v \delta \alpha \lambda i \zeta o \mu \alpha$ from his sources Matthew and Luke. However, this is to assume their own hypothesis in the determining of characteristic language, and so to bind themselves into the same kind of circle that they criticize in others.

Furthermore, although Hawkins's, Goulder's, Gundry's, Luz's and Davies-Allison's word-lists are all influenced by source considerations, ${ }^{37}$ it needs to be noticed that they all include figures from each of the three synoptics not purely because they think that there are interrelationships among the synoptics but also because they are comparing like with like. The three synoptics deal with the same subject matter and provide potentially helpful ways of determining characteristic vocabulary. It is worth noting, for example, that Goulder thinks that Matthew used Mark alone before Luke was even written, yet he includes figures from Luke in his list of characteristic Matthaean vocabulary. ${ }^{38}$ Similarly, Hawkins thinks that Mark was written before Matthew and Luke appeared, but he includes figures from Matthew and Luke in his list of characteristic Markan vocabulary. ${ }^{39}$ It will not do, then, for the Research Team to take Mark out of their calculations.

One more word of caution is necessary. Often in the book the linguistic argument has it too easy. Sometimes just one Matthaean 'linguistic usage' appearing in Luke is regarded as adequate evidence for 'Luke's use of Matthew' (as in the case of $\sigma \kappa \alpha v \delta \alpha \lambda i \zeta o \mu \alpha$ above) and equally, a small number of words in non-Matthaean sections can count as 'considerable evidence of Lukan composition' (this phrase, p. 61). Thus

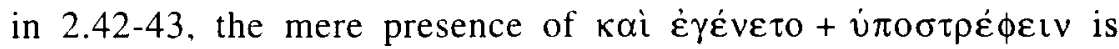
regarded as 'evidence for Lukan composition' (p. 69).

But composition can be more (and less!) than just a handful of characteristic expressions. The Research Team might themselves have been placed on their guard, for example, by the fact that Lk. 7.1, one of their key 'one-way indicators' (p. 22), features much characteristic

Horae Synopticae, p. 33 with figures of 4/1/1. On the assumption of Markan priority, this usage is inserted redactionally by Matthew in 26.31 (see Goulder and the Gospels, p. 67).

37. See Goulder and the Gospels, pp. 44-47.

38. See Michael Goulder, Midrash and Lection in Matthew (London: SPCK, 1974), pp. 477-85.

39. Hawkins, Horae Synopticae, pp. 10-15. 
Lukan vocabulary, and not a word in common with Matthew. ${ }^{40}$ If this verse had had no parallel in Matthew, it is clear that it would have been regarded as 'compositional', and not as being dependent on a source.

Here, then, we are touching on the repeated argument from 'one-way indicators'. If there are questions over the way that the Research Team use Lk. 7.1, what of the other examples? Let us look at the comments on Lk. 13.28:

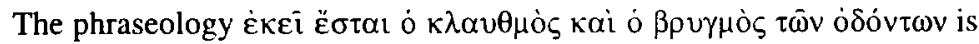
characteristic of the text of Matthew (cf. Tevis, Display, 206). This is the only appearance of this Matthean phrase in Luke. Its occurrence in a parallel literary context with Matthew is strong evidence that Luke used the canonical Gospel of Matthew, not a source such as 'Q' (p. 206).

This kind of argument has also been used much by Michael Goulder, who stresses this same example. ${ }^{+1}$ How is one to assess it? Do we here have decisive evidence for 'Luke's use of Matthew'? The most reliable means of assessing this evidence is the application of a simple test, a test that proves, unfortunately, that the 'one-way indicator' actually points two ways.

In my recent Goulder and the Gospels, I take all the vocabulary that occurs in common to both Matthew and Luke in double tradition passages and screen the words to see how many of them are characteristic of Matthew and how many are characteristic of Luke. Both the Griesbach Hypothesis and the Farrer Hypothesis (Goulder's) postulate Luke's knowledge of Matthew, and under both hypotheses one might have expected to find a huge predominance of Matthaean vocabulary and only a limited number of Lukan words. But this is not the case. After the painstaking work of listing, sifting, counting and comparing is over, one finds that the scores are even: among the shared words there are as many Lukanisms as there are Matthaeanisms.

To take the above example of 'weeping and gnashing of teeth', this is one of only two words or expressions that are strongly Matthaean in the pericope Mt. 8.5-13 (the other being $\dot{\alpha} v \alpha \tau 0 \lambda \eta \dot{\eta}, 5 / 0 / 2$ ). In Luke's paral-

40. This is acknowledged by the Research Team: 'Luke has clearly re-written Mt. 7.28a in his own idiom' (p. 108). The relevant verses are only given in English in the introduction (pp. 22-23); and one might contrast the synopsis in Greek on p. 103 which demonstrates the lack of verbal parallel in spite of the comment above the synopsis about 'Luke's use of the concluding phrase[o]logy at the end of Mt's Sermon on the Mount'.

41. For example, see Luke: A New Paradigm, p. 12. 
lels to the pericope $(7.1-10 ; 13.28-29)$, there are three strongly charac-

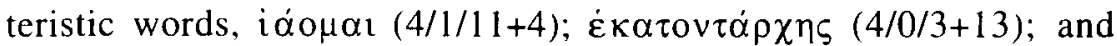
iкavós $(3 / 3 / 9+18)$. $^{+2}$

The same pattern is often repeated, and many examples of Lukanisms among the shared words, to match the Matthaeanisms, could be given. It might be objected, of course, that the criteria I use for 'characteristic' and 'strongly characteristic' are those of Hawkins and Goulder, and thus these results are irrelevant to the Griesbach Hypothesis and the current volume. But a careful study of Research Team's preferred tool, Franklyn Collison's 'Linguistic Usages', reveals the presence of the same phenomenon.

In the same pericope, Mt. 8.5-13// Lk. 7.1-10; 13.28-29, for example, one will find three Lukan 'linguistic usages' among the shared words, 'non-telic use of 'iva' (a 'likely' usage-Collison, p. 115): $\dot{\varepsilon} \xi_{0}$ ovoia (a 'certain' usage, p. 173) and $\ddot{\alpha} v \theta \rho \omega \pi \circ \varsigma=\tau ı \varsigma$ (a 'probable' usage, pp. 211-12).

Lest this is an unusual case, let us also take one of the authors' other preferred examples, the occurrence of $\sigma \kappa \alpha v \delta \alpha \lambda i \zeta o \mu \alpha \mathrm{l}$ in Mt. $11.6 / / \mathrm{Lk}$. 7.23 (pp. 24 and 115). In this same pericope (Mt. 11.2-19 // Lk. 7.1835 ), among the shared words, ${ }^{+3}$ there are nine of Collison's Lukan 'linguistic usages': $\dot{\alpha} \pi \alpha \gamma \gamma \dot{\varepsilon} \lambda \lambda \omega$ ('probable' usage, p. 38); $\varepsilon \dot{\cup} \alpha \gamma \gamma \varepsilon \lambda i \zeta o \mu \alpha$

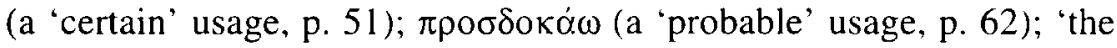
use of $\ddot{\eta}$ as a disjunctive particle between two parallel or supplementary questions' (a 'probable' usage, pp. 105-106); 'the use of $\dot{\varepsilon} \alpha \dot{\alpha} v$ for $\ddot{\alpha} v$,

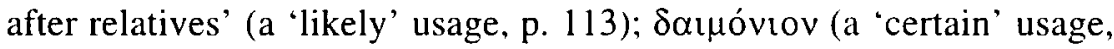

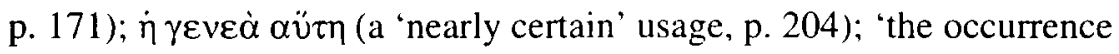
of ö $\zeta$ which includes within itself a demonstrative pronoun' (a 'nearly certain' usage, pp. 205-206); and öv $\theta \rho \omega \pi \mathrm{s}=\tau \iota \varsigma$ (a 'probable' usage, pp. $211-12){ }^{H}$

42. For full details, see Goulder and the Gospels, pp. 61-62. Note that there is an error here - $\ddot{\alpha} \gamma \omega$ does not feature in either Matthew or Luke here and should be

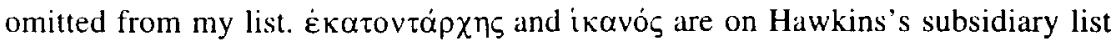
for Luke which takes into account the occurrences from Acts. Note also in this pericope that there are more 'semi-Lukan' words than there are 'semi-Matthaean' words.

43. For comment on the characteristic vocabulary in this pericope, and full list of characteristically Matthaean and characteristically Lukan words (on Hawkins's and Goulder's criteria), see Goulder and the Gospels, pp. 66-69 and 83.

44. Collison also lists ' $\pi \varepsilon \rho i$ $\alpha \dot{v} \tau o \bar{v}$, of Jesus' as a 'certain' linguistic usage that occurs among the shared words in this pericope ('7.27 = Mt', p. 140). However, the 
One can see the problem with one-way indicators, however, even without looking at my work, or consulting Collison, for the argument is refuted from within the text of Beyond the $Q$ Impasse itself. On p. 118. where the authors are discussing Lk. 7.50, they list the occurrences of $\dot{\eta}$ $\pi i \sigma \tau \iota \varsigma$ бov $\sigma \dot{\varepsilon} \sigma \omega \kappa \dot{\varepsilon} v \sigma \varepsilon$. It is, they say, "clearly due to Luke's compositional activity' and occurs again in Lk. 8.48, 17.19 and 18.42 and Mt. 9.22 (narrative, sequential parallel to Luke 8.48). If it had been the other way round, an expression coming four times in Matthew and only once in Luke, in close narrative, sequential parallel, it would have been regarded as a "one-way indicator".

The case from 'one-way indicators', therefore, is falsified, whether one uses Hawkins's, Goulder's or Collison's criteria. The presence of plenty of counter-examples do not permit the authors' data to carry any weight.

\section{Conclusion}

Beyond the $Q$ Impasse is the most important book yet produced by those working with neo-Griesbachian assumptions. It goes beyond anything that those wanting to 'renew Gospel studies' have achieved so far. And it has some real strengths. On the question of order, for example, the authors have presented a clear, coherent case which will facilitate further study, and reward careful investigation, especially as it relates to the question of Luke's literary ability.

But the book has weak points too. Weakest of all is the linguistic argument, which does not stand up to scrutiny. The evidence from 'oneway indicators' is contradicted by linguistic usages that go the opposite way from that desired by the authors. There are also some serious question-marks over the authors' strategy. They have attempted to 'set forth a better way' than traditional scholarship and to address all the key questions by 'working as an interdisciplinary team using impartial instruments, taking Mark completely out of the picture and dispensing with $Q^{\prime}$ (p. 12; their emphasis).

This 'better way' has snares unforeseen by the Research Team. The tools are not impartial, and to take Mark 'completely out of the picture' draws one into a circle from which it is difficult to emerge. By ignoring

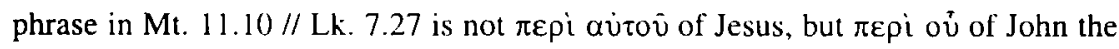
Baptist. 
the evidence from Mark, the data the authors present becomes prejudiced in their own favour. To talk about pericopae shared by Mark and Luke as 'unique to Luke', to discuss language without looking at parallel usages in Mark, and to consider order without any reference to Mark, will probably prejudice many against taking this volume seriously.

It is easy to see how this situation has arisen. Defenders of the Griesbach Hypothesis have been arguing the case for Markan posteriority for years, usually in relation to the question of Mark's use of Matthew and Luke. When turning to Luke, therefore, $Q$ comes into focus and Mark appears less relevant. However, in dealing with Luke, the discussion of the priority of Mark ought to be just as important as discussion of Q, and a book about Luke's use of Matthew alone should be a book that attempts to go not just Beyond the $Q$ Impasse but also beyond the priority of Mark consensus.

Thus, the question that Markan priorists consistently find themselves asking is: Does this material make better sense as Luke's reworking of Mark or as Luke's reworking of Matthew? This question is all the more important since for most. dispensing with $Q$ is higher on potential agendas than is abandoning the priority of Mark, especially in the United Kingdom, where the main challenger to the Two-Source Hypothesis remains the Farrer Hypothesis, and not Griesbach.

Perhaps, though, the Research Team are not far from Farrer. Appeals to Luke's dependence on 'nonMatthean tradition' in cases like Lk. 4.31-37 // Mk 1.21-28 (Capernaum Synagogue, pp. 88-9) or Lk. 21.1-4 // Mk 12.41-44 (Widow's Mite, p. 257) sound, after all, rather like appeals to Lukan dependence on Mark. ${ }^{+5}$ And there are even places where Markan priority sneaks in the back door. Before discussing Lk. 5.17-26, the authors provide their usual lively summary of the pericope's content and begin, 'One day Jesus is in a house teaching when suddenly...' (p. 96; my emphasis). But there is no house at the beginning of Luke's account-the Research Team have picked up the detail from Mark! In the Lukan version, the men go through the roof of a house that Luke has not mentioned. Perhaps Luke, after all, is just as familiar with Mark as are the Research Team. ${ }^{\text {th }}$

This volume will not convince the scholarly world about 'Luke's use

45. I am indebted to Stephen Carlson for this point.

46. For further discussion of this example, see my 'Fatigue in the Synoptics', NTS 44 (1998), pp. $45-58$ (pp. 49-50, 53). 
of Matthew . Yet some will surely feel that the enterprise is redeemable, and will be all the more persuaded, after having read it, that the only way to go beyond the $Q$ impasse will be to walk hand-in-hand with Markan priority. ${ }^{47}$

\begin{abstract}
Beyond the Q Impasse: Luke's Use of Matthew attempts to explain the composition of the Gospel of Luke on the assumption of the Griesbach hypothesis. This review article analyses the book's scope, strategy and methodology and focuses on arguments from order and language. It concludes that in spite of strengths like clarity of presentation and a stress on Luke's literary ability, Beyond the $Q$ Impasse suffers from lack of engagement with the secondary literature, circularity and a flawed linguistic argument. While the book is an important contribution to studies of the Synoptic Problem, it is unlikely to convince scholars that Luke used Matthew alone.
\end{abstract}

47. I spotted the following printing errors in the book: p. 11: second line from

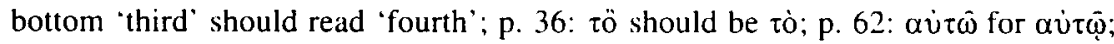
p. 65: 'Eıрท் quoting Mt. 13.54); p.100, on v. 25 and 12.15b: avití for $\alpha \dot{v} \tau \hat{\omega} ;$; p. 101, on 5.1:

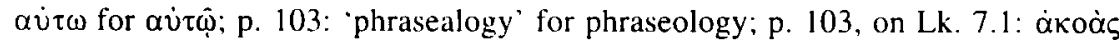
has collided with tovi; p. 177, 'ntoice'; p. 182, ò for tò; p. 321, 'of of'; p. 191, 'wasw'; p. 198, 'aqnd'; p. 331: the reference to 'Neirynck' should be xi, not i. Likewise 'Tuckett', should be xi, not i. 